\title{
Simulation Study on Indoor Ground Condensation Prevention by House Natural Ventilation Controlling for Rural Residential in Chongqing, China
}

\author{
Dong Wang, Ming-fang Tang ${ }^{*}$,Jin-zhong Fang
}

Faculty of Architecture and Urban Planning, Key Laboratory of New Technology for Construction of Cities in Mountain Area, Chongqing University, Chongqing 400045, China

${ }^{*}$ Corresponding author: tmf@cqu.edu.cn

\begin{abstract}
Keywords: Rural residential environment; Indoor ground; Condensation prevention; Natural ventilation control; DesignBuilder \& EnergyPlus simulation

Abstract: In this paper, we study a new way to prevent indoor ground condensation by controlling natural ventilation between outdoor and indoor, it adjust to reduce the indoor dew point temperature lower than the ground surface temperature as much as possible, so to prevent condensation. Through make a typical rural house model used for ICC software DesignBuilder, we have a simulation of controlling natural ventilation by changing ventilation opening area, thereby controlling indoor ground condensation hours. Studies have shown that: between March to July, simulate house model in the natural ventilation passive state with $100 \%$ full opening of the wall, there is a total maximum number of condensation hours of a rural house model; by changing percentage of ventilation opening area, it can significantly control the condensation hour number; it is not entirely a monotonic relationship between the changing of the number of condensation hours and the changing of ventilation opening area; in simulation, when increasing percentage of ventilation opening area from $30 \%$ to $100 \%$, the number of condensation hours has a condensation fluctuations, not simply a monotonically increasing.
\end{abstract}

\section{Introduction}

The current study has been carried out in the rural residential thermal environment, mostly about the winter cold, summer heat of interior thermal environment[1-2], but for the hot-humidity areas, there are also interior moisture problems. Chongqing is a typical hot summer and cold in winter, hot and humidity in summer, cold and wet winter, especially wet transition season, annual average relative humidity of about $85 \%$. It was reported[3], when the interior air humidity greater than $70 \%$, interior mold began to appear; when greater than $75 \%$, the dust deposited on the propagation of bacteria will accelerate; when greater than $85 \%$, building materials wet feeling, wood system material begins to corrode; when greater than $90 \%$, accelerating the propagation of microorganisms, moldy wall surface. Interior long in a wet state will seriously affect human health. In the 《Evaluation standard for interior thermal environment in civil buildings GB/T 50785-2012》 claim three can not be an interior condensation and mildew[4]. So it is very necessary to research the Moisture Situation of rural residential in hot-humidity areas.

\section{Research idea and model simulation}

In Chinese hot-humidity areas, the traditional structure of farm house indoor ground is a compaction layer direct on the earth natural soil as a basement layer. On the one hand, the structure has the combination of traditional practices, local conditions, economical and practical, and has the most advantage of making the indoor air temperature "Warm in Winter and Cool in Summer"(Table 1.).On the other hand, the structure make the indoor ground condensation prevention become the focus problem of the farmhouse study, it is easy to dew in hot-humidity transition season of spring and summer. 
At present, the relevant standards and engineering practice, mainly use ground insulation to increase ground surface temperature, which do some extent to prevent condensation. But the effect is quite limited:

a) It can be used in new buildings, but it can hardly be applied indoor ground an additional insulation layer to existing traditional old building;

b) It requires a higher cost and it require higher construction technology;

c) It is no longer to have the advantage of making the indoor air temperature "Warm in Winter and Cool in Summer".

\section{Research idea}

For the Chinese traditional farm house indoor ground, in the hot and humid season, the order of heat transfer, form bottom to top is:

a) Earth soil body. which corresponds to the cold source in a certain depth of soil - according to the principle of thermal this earth soil temperature change in long time by month, it is "Warm in Winter and Cool in Summer", in spring and summer, the soil temperature is significantly lower than the natural indoor and outdoor air temperatures. It is the low-temperature side of the heat transfer process.

b) Soil compaction layer direct on the natural soil as a basement layer.

c) The building indoor ground surface layer on the basement layer.

d) Indoor ground surface air layer.

e) Indoor air. It is the high-temperature side of the heat transfer process.

Table 1. Average temperature $\left({ }^{\circ} \mathrm{C}\right)$ monthly in Chongqing Standard meteorological year.

\begin{tabular}{|c|c|c|c|}
\hline $\begin{array}{c}\text { Average temperature } \\
\text { monthly }\end{array}$ & $\begin{array}{c}\text { Earth natural soil } \\
\text { ENST }\left({ }^{\circ} \mathrm{C}\right)\end{array}$ & $\begin{array}{c}\text { Outdoor air } \\
\text { temperature OAT }\left({ }^{\circ} \mathrm{C}\right)\end{array}$ & $\begin{array}{c}\text { ENST - OAT } \\
\left({ }^{\circ} \mathrm{C}\right)\end{array}$ \\
\hline March & 9.4 & 13.3 & -3.9 \\
\hline April & 10.1 & 18.0 & -7.9 \\
\hline May & 14.3 & 23.1 & -8.8 \\
\hline June & 19 & 25.3 & -6.3 \\
\hline July & 23.3 & 28.1 & -4.8 \\
\hline
\end{tabular}

Therefore, to prevent indoor ground surface condensation can be in two ways:

a) On the one hand, we can increase in the surface temperature of the indoor ground surface by getting the indoor ground an additional insulation layer, so dew can be prevent to some extent, it is the normal practice.

b) On the other hand, we can lower the indoor air water vapor partial pressure - to lower its dew point temperature, dew can also be prevent to some extent, it is this paper research ideas.

It is very necessary to emphasis: there are many differences on their mechanism of action, their effect on the relevant parameters:

a) The first way, it add ground insulation layer to prevent condensation, the role of a single subject only to increase the surface temperature of the indoor ground, it will not affect the indoor water vapor dew point temperature.

b) While the second way, its role is multifaceted, and it is not only mainly controlled water vapor partial pressure and dew point temperature, but also followed inevitably affect the indoor air temperature, thus affecting the heat transfer between the earth soil (its equivalent of a cold source) under indoor ground and the indoor air, so it has a certain extent effect on the the surface temperature of the indoor ground.

\section{model}

We make a DesignBuilder \& EnergyPlus simulation model with a real typical farm house as show in Fig. 1. 

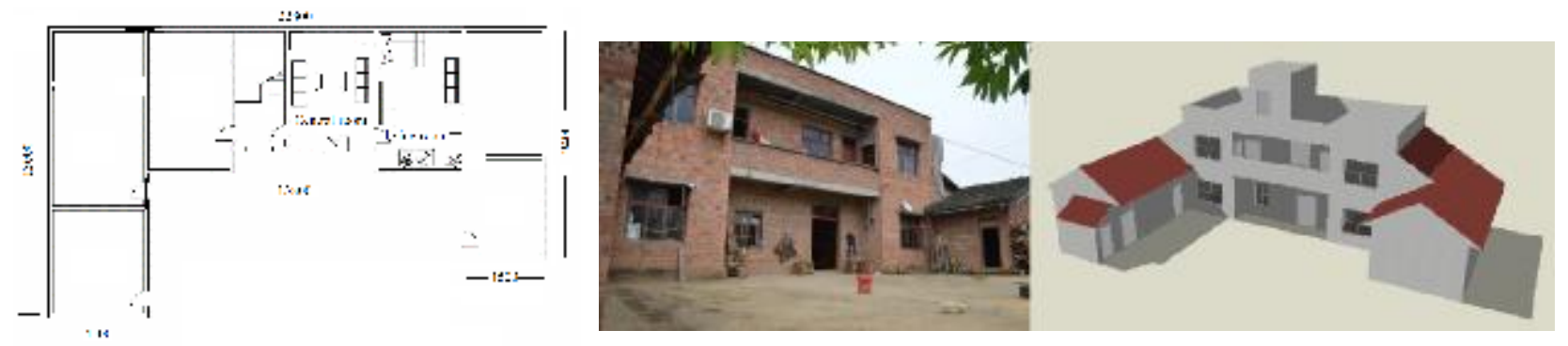

Fig. 1. Farm house photograph, plan \& DesignBuilder \& EnergyPlus simulation model images. simulation

\section{simulation}

The DesignBuilder \& EnergyPlus simulation model has a real typical farm house construction: walls made of brick; the roof is flat concrete roof and watt sloping roof; indoor ground floor made of compacted soil, stone cushion and slag concrete surface, door and window made of wood and Single glass. They are common and cheap. There was no structure to maintain professional insulation layer. Set the DesignBuilder \& EnergyPlus simulation to natural ventilation mode. Successive change the percentage of open ventilation area to wall area of the central room \& living room, have simulation one by one. Recording the number of condensation, the indoor air temperature, indoor air dew point temperature, the indoor ground surface temperature, making charts and tables.

\section{Simulation Analysis}

It is apparent by changing percentage of open ventilation area, it can significantly control the condensation hour number as shown in Table 2. We selected a typical period From April 21st 00:00 to April 25th 23:00 in Chongqing Standard meteorological year. As shown in Table 3, from April 21st 00:00 to April 25th 23:00, it has just a total of 120 hours, it is 70 ground condensation hours with $80 \%$ opening, while it is 41 ground condensation hours with $50 \%$ opening. For example, the Farm householder can reduce his house ground condensation hours from 70 to 41 (the equivalent of playing off 6), just close his door and window's open ventilation area from $80 \%$ to $50 \%$, without pay for any expensive professional insulation layer construction.

It also show the fluctuation of indoor air temperature, air dew point temperature and ground surface temperature with the changing of opening as Fig. 2. Fig. 3. So they are not simple linear relationship, different house model has different fluctuation data fluctuation. The simulation is very necessary, In particular, in the design phase.

Table 2. Indoor ground condensation hours number monthly with different percentage of open ventilation area to wall area.

\begin{tabular}{ccccccccc}
\hline Percentage & $30 \%$ & $40 \%$ & $50 \%$ & $60 \%$ & $70 \%$ & $80 \%$ & $90 \%$ & $100 \%$ \\
\hline March & 0 & 0 & 0 & 0 & 0 & 0 & 8 & 8 \\
April & 0 & 19 & 62 & 101 & 85 & 105 & 135 & 106
\end{tabular}

Table 3. Indoor ground condensation hours number with different percentage of open ventilation area to wall area From April 21st 00:00 to April 25th 23:00.

\begin{tabular}{cccccccc}
\hline Percentage & $40 \%$ & $50 \%$ & $60 \%$ & $70 \%$ & $80 \%$ & $90 \%$ & $100 \%$ \\
\hline Hours number & 0 & 41 & 51 & 48 & 70 & 64 & 33
\end{tabular}

\section{Conclusion}

Studies have shown that:

a) Between March to July, simulate house model in the passive state with opening area of ventilations, there is a total maximum number of condensation hours of a rural house model.

b) By changing percentage of ventilation opening area, it can significantly control the condensation hours number. 
c) In simulation, when increasing percentage of ventilation opening area from $0 \%$ to $100 \%$, the number of condensation hours has a condensation fluctuations, not simply a monotonically increasing, but it has a maximum value. It is not entirely a monotonic relationship between the changing of the number of condensation hours and the changing of ventilation opening area.

d) Simulation studies show that: changing percentage of ventilation opening area - controlling natural ventilation - controlling indoor ground surface condensation hours, it is not only a feasible and effective and innovative research idea, approache, but also a simple practical feasible good way.
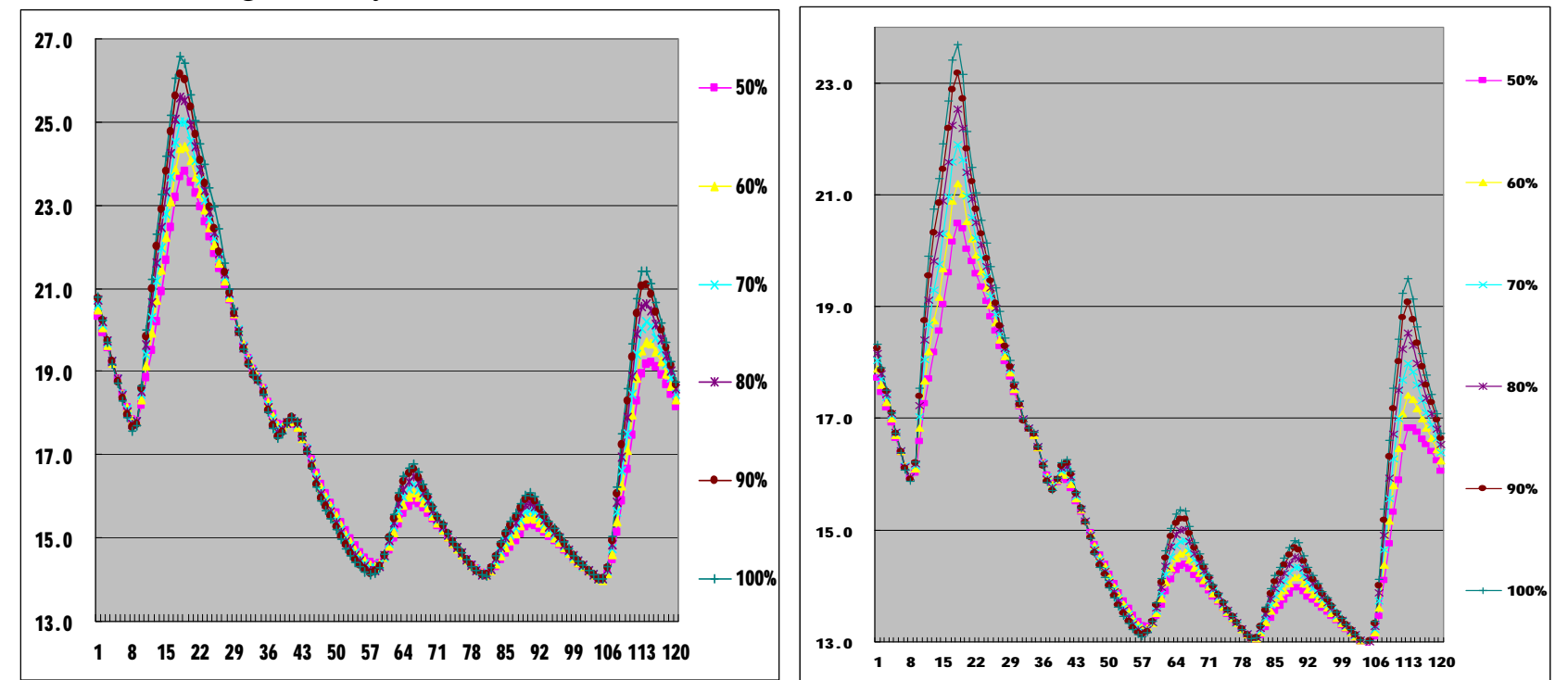

Fig. 2. Left. Indoor air temperature fluctuation with different percentage of open ventilation area to wall area. Fig. 3. Rght. Indoor ground surface temperature fluctuation with different percentage of open ventilation area to wall area. From April 21st 00:00 to April 25th 23:00.

\section{Acknowledgements}

The supports for research by National Natural Science Foundation Project (51478059) in China are gratefully acknowledged.

\section{References}

[1] Tang Fang-wei, Hu Rong-rong, Liu Jia-ping, Cheng Hui. 2011. Measurement Analysis on Indoor Thermal Environment in Summer in Sichuan Traditional Dwellings, J. Building Science 27(6) 15-18. (in Chinese)

[2] Song Ping, Tang Ming-fang, Zheng Kai-li. 2015. Actual Measurement and Evaluation of Thermal Environment of Rural Residential Buildings in Chongqing, J. Building Science 31(6) 118-123. (in Chinese)

[3] Yu Xiao-ping, Fu Xiang-zhao. 2002. A Perspective of Indoor Air Quality and the International Standard of Ventilation. J. Journal of ChangDu Textile College 19(3)35-38. (in Chinese)

[4] GB/T 50785-2012 Evaluation standard for indoor thermal environment in civil buildings, China Architecture \& Building Press, Beijing, 2012, pp. 5-9. (in Chinese) 